\title{
[3.3]Dithia-bridged cyclophanes featuring a thienothiophene ring: synthesis, structures and conformational analysis
}

\author{
Sabir H. Mashraqui ${ }^{* 1}$, Yogesh Sanghvikar ${ }^{1}$, Shailesh Ghadhigaonkar ${ }^{1}$, \\ Sukeerthi Kumar ${ }^{1}$, Auke Meetsma ${ }^{2}$ and Elise Trân Huu Dâu ${ }^{3}$
}

\section{Full Research Paper}

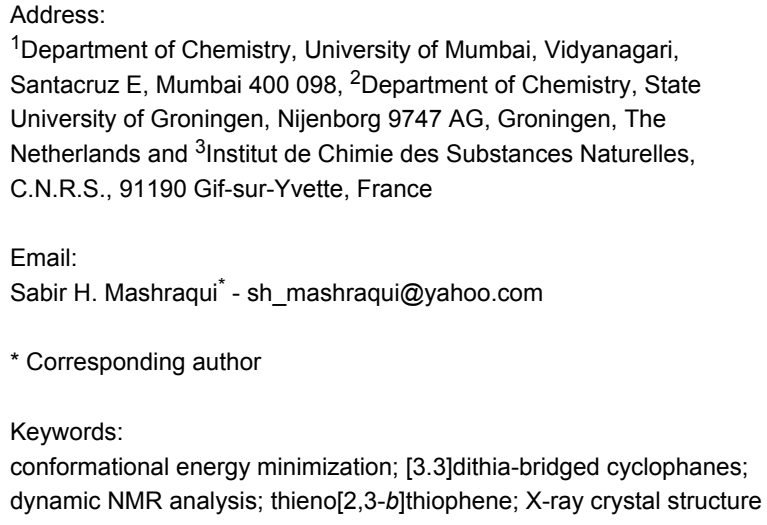

${ }^{1}$ Department of Chemistry, University of Mumbai, Vidyanagari, Santacruz E, Mumbai 400 098, ${ }^{2}$ Department of Chemistry, State University of Groningen, Nijenborg 9747 AG, Groningen, The Netherlands and ${ }^{3}$ Institut de Chimie des Substances Naturelles, C.N.R.S., 91190 Gif-sur-Yvette, France

Email:

Sabir H. Mashraqui ${ }^{*}$ - sh_mashraqui@yahoo.com

* Corresponding author

Keywords:

conformational energy minimization; [3.3]dithia-bridged cyclophanes; dynamic NMR analysis; thieno[2,3-b]thiophene; X-ray crystal structure

Beilstein Journal of Organic Chemistry 2009, 5, No. 74. doi:10.3762/bjoc.5.74

Received: 06 October 2009

Accepted: 26 November 2009

Published: 08 December 2009

Editor-in-Chief: J. Clayden

(c) 2009 Mashraqui et al; licensee Beilstein-Institut. License and terms: see end of document.

\begin{abstract}
The synthesis of [3.3]dithia-bridged cyclophanes 7, 9 and $\mathbf{1 1}$ incorporating a fused heterocycle, thieno[2,3-b]thiophene is described. The structures are established by ${ }^{1} \mathrm{H}$ NMR analysis and, in the case of 11, also by single crystal X-ray crystallography. Conformational analysis by variable temperature NMR suggests that cyclophanes 7, 9 and $\mathbf{1 1}$ exhibit conformationally rigid bridges and rings at least up to $130{ }^{\circ} \mathrm{C}$. Energy minimization of $\mathbf{1 1}$ revealed anti-11 to be the most stable conformation. Although, the computed energy difference between the most stable conformation anti-11 and the next higher energy conformation syn-anti-11 is only $2.98 \mathrm{~kJ} / \mathrm{mol}$, it is intriguing that $\mathbf{1 1}$ does not exhibit thia-bridge inversion even at elevated temperatures.
\end{abstract}

\section{Introduction}

The synthesis, molecular structures and conformational dynamics of short-bridged cyclophanes continue to engage interest in supramolecular chemistry [1-4]. The study of the conformational dynamics of cyclophanes has greatly enriched our fundamental understanding with regard to the structural features governing the energy barriers to ring inversion processes in these molecules $[5,6]$. Structural factors that have bearing on the conformational energy barriers of the ring and bridges in cyclophanes include the type the rings, nature of inner substituents and the length of the bridges encompassing the ring(s). Temperature dependent conformational behaviors of a diverse variety of [1.3]dithia-cyclophanes have been studied 
extensively and depending upon structural features both conformationally restricted and freely interconverting thiabridged systems have been identified [7-17].

Cyclophanes incorporating simple heteronuclei such as furan, thiophene, pyridine, pyridazine and benzothiazole are abundantly known [1-3]. Despite the known structural diversity and complexity of cyclophanes, it is surprising that cyclophanes featuring fused heteronuclei have scarcely been studied [18-20]. Lately, we have been exploiting the thieno[2,3-b]thiophene ring, a fused heterocycle towards creating potentially interesting intramolecular charge transfer [21], nonlinear optics [22] and axially chiral systems [23]. We have also recently incorporated a thienothiophene ring within the cyclophane framework via its 3,4-positions, leading to the synthesis of meta type 1,3dithia-bridged thienothiophenophanes 1-2 [24]. Cyclophanes 1-2 (Figure 1) have been found to exhibit thia-bridge inversion down to $-50{ }^{\circ} \mathrm{C}$ with an estimated energy barrier $>25 \mathrm{~kJ} \mathrm{~mol}^{-1}$. In the present work, we deemed it of interest to exploit the other available positions of the thienothiophene ring, namely the 2,5 positions to access a new set of bridged [3.3]dithia-thienothiophenophanes 7, 9 and $\mathbf{1 1}$. Our main objective in the synthesis of these cyclophanes was to evaluate their structures and conformational properties.

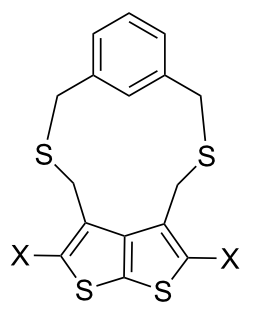

$$
\begin{aligned}
& \text { 1: } X=-\mathrm{COOC}_{2} \mathrm{H}_{5} \\
& \text { 2: } X=-\mathrm{H}
\end{aligned}
$$

Figure 1: Conformationally flexible 3, 4-bridged dithia-thienothiophenophanes.

\section{Results and Discussion \\ Synthesis of dithia-thienothiophenophanes 7, $\mathbf{9}$ and $\mathbf{1 1}$}

2,5-Bis(chloromethyl)-3,4-dimethylthieno[2,3-b]thiophene (5) required as a precursor to construct cyclophanes 7, 9 and $\mathbf{1 1}$ was prepared as outlined in Scheme 1. The starting material, thienothiophene diester 3 was readily prepared in multigram quantities by a modification of our procedure [25]. Reduction of $\mathbf{3}$ with $\mathrm{LiAlH}_{4}$ in dry THF, followed by basic aqueous work-up gave diol 4 in $91 \%$ yield. The reaction of 4 with $\mathrm{SOCl}_{2}$ in dry dichloromethane $\left(5-10{ }^{\circ} \mathrm{C}, 5 \mathrm{~h}\right)$, followed by solvent removal and crystallization from petroleum ether afforded dichloride 5 in $88 \%$ yield, m.p. $161-163{ }^{\circ} \mathrm{C}$. The coupling reaction of 5 with m-xylenedithiol 6 was carried out in dry $\mathrm{DMF} / \mathrm{K}_{2} \mathrm{CO}_{3}$ under high dilution conditions and under $\mathrm{N}_{2}$ atmosphere. The crude solid obtained on work-up was purified by column chromatography on $\mathrm{SiO}_{2}$ affording the desired meta dithia[3.3]cyclophane 7, m.p. $247-250{ }^{\circ} \mathrm{C}$ as a colorless solid in $57 \%$ yield. Likewise, the para dithia-bridged thienothiophenophanes $\mathbf{9}$ and $\mathbf{1 1}$ were prepared by coupling dichloride 5 with dithiols 8 and 10 respectively under the conditions described for 7 . The crude products from these reactions were purified by column chromatography on $\mathrm{SiO}_{2}$ to furnish the corresponding dithia-cyclophanes 9 and $\mathbf{1 1}$ in $50 \%$ and $10 \%$ yields respectively.

\section{NMR assignments and conformational analysis of thienothiophenophanes 7, 9 and 11}

The ${ }^{1} \mathrm{H}$ NMR (300 MHz) spectrum of dithia-cyclophane 7 revealed two $\mathrm{AB}$ spin systems $(4 \mathrm{H}$ each) in the range of $\delta 3.21-4.30$ due to the geminal couplings of the bridged $-\mathrm{CH}_{2}-$ protons. A singlet centered at $\delta 2.31$ accounted for the $\mathrm{C} 3 / \mathrm{C} 4$ methyl groups. The adjacent aromatic $\mathrm{H} 4, \mathrm{H} 5$ and $\mathrm{H} 6$ protons appeared as a multiplet $(3 \mathrm{H})$ centered at $\delta 7.32$, whereas the isolated internal $\mathrm{H} 2$ proton appeared as a sharp singlet $(1 \mathrm{H})$ at $\delta 6.03$. The higher field position of the internal $\mathrm{H} 2$ compared to the chemical shifts of H4-H5-H6 protons is presumably due to the shielding anisotropic effect of the facing thienothiophene ring.

The ${ }^{1} \mathrm{H}$ NMR (700 MHz) spectrum of dithia-cyclophane 9 showed two sets of $\mathrm{AB}$ type spin systems, comprising doublets at $\delta 3.65(2 \mathrm{H}, J=15 \mathrm{~Hz}), 3.72(2 \mathrm{H}, J=14 \mathrm{~Hz}), 3.73(2 \mathrm{H}, J=$ $15 \mathrm{~Hz})$ and $4.08(2 \mathrm{H}, J=14 \mathrm{~Hz})$. The appearance of two AB type spin systems implies that the methylene protons attached to one side of the bridge are magnetically identical with their respective counterparts on the other side of the bridge. A singlet located at $\delta 2.19$ is due to the methyl protons, whereas the phenyl ring protons appear as sharp singlets at $\delta 6.84$ and 6.95 (2H each). Appearance of two singlets for the para bridged phenyl ring implies that the two sides of the phenyl ring are subject to differing magnetic fields on account of the unsymmetrical nature of the facing thienothiophene ring.

The ${ }^{1} \mathrm{H}$ NMR of 11 showed a 16 line resonance ( $\delta 3.36$ to 4.30 ) expected for the $\mathrm{AB}$ type coupling of its four unique sets of bridge methylene protons. Each of the $-\mathrm{CH}_{3}$ groups and $-\mathrm{OCH}_{3}$ groups appear as separate singlets observed at $\delta 2.20$, 2.31 and $3.75,3.82$, respectively. The nonequivalence of otherwise chemically identical pair of $-\mathrm{CH}_{3}$ as well as $-\mathrm{OCH}_{3}$ group of protons can be attributed to the differing magnetic environments around these groups created by the facing thienothiophene and the phenyl rings. Although, in analogy to the 

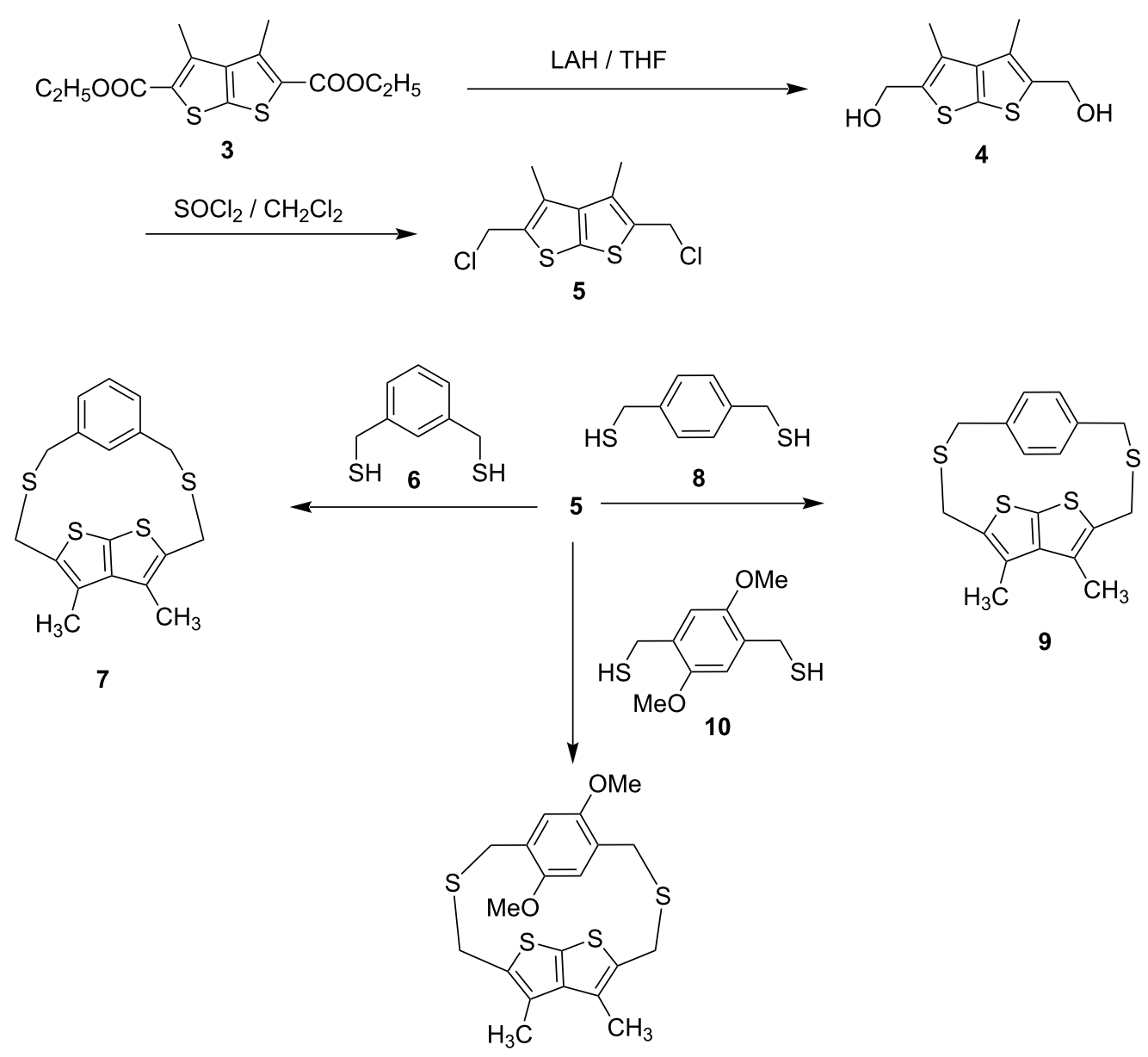

11

Scheme 1: Synthetic scheme for compounds 7, 9 and 11

$-\mathrm{CH}_{3}$ and $-\mathrm{OCH}_{3}$ protons, we expected the phenyl ring protons to also appear as two separate singlets, however in practice we observe only one singlet at $\delta 6.80(2 \mathrm{H})$. This may presumably be due to their coincidental chemical shift equivalence.

The bridge $-\mathrm{CH}_{2}-$ protons in dithia-bridged cyclophanes 7, 9 and $\mathbf{1 1}$ resonate as geminally coupled $\mathrm{AB}$ systems. From these results, we infer that the bridge inversions in these molecules are restricted on the NMR time scale at ambient temperatures. Furthermore, since phenyl ring protons in $\mathbf{9}$ and methoxy protons in $\mathbf{1 1}$ resonate at two different chemical shifts, we can conclude that aryl ring rotations in these molecules also seem to be conformationally restricted. Higher temperatures might surpass the conformational energy barrier, allowing the molecules to undergo free bridge and ring inversions [26]. In the event of free bridge rotations, the geminally coupled systems would coalesce into two sharp singlets corresponding to the two different sets of the bridged $-\mathrm{CH}_{2}-$ protons. On the other hand, ring rotation in $\mathbf{9}$ and $\mathbf{1 1}$ would convert separate signals for the phenyl ring and methoxyl protons into singlets due to the fast interconversion of ring conformers. Accordingly, we recorded variable temperature NMR spectra of dithia-cyclophanes 7, 9 and $\mathbf{1 1}$ at different intervals from room temperature to $130{ }^{\circ} \mathrm{C}$ in DMSO- $d_{6}$. However, no changes were noticeable in the multiplicities of the bridge $-\mathrm{CH}_{2}-$ protons with the aryl ring and methoxy protons also retaining their separate chemical shift positions. These observations suggest the absence of bridge flippings and ring rotations in these systems at least up to $130{ }^{\circ} \mathrm{C}$ with an estimated conformational energy barrier of $>100 \mathrm{~kJ} \mathrm{~mol}^{-1}$ [27]. The presence of substituents on the thienothiophene ring (as well as on the phenyl ring in 11) and the absence of conformational inversion endow these with molecular chirality rendering them potentially resolvable.

Temperature dependent conformational behaviors have been reported for a number of unsubstituted [1.3] dithia-cyclophanes $[5,6]$. However, replacing internal hydrogen atoms of the thienothiophene with a bulky substituent viz. $-\mathrm{CH}_{3}$ in 
[1.3]dithia- and related cyclophanes raises the conformational energy barriers sufficiently to render such systems conformationally immobile [28-31]. By analogy, it is reasonable to assume that the conformational restrictions of the bridges and rings observed in the presently synthesized cyclophanes could at least in part be due to the presence of methyl substituents on the thienothiophene rings in $\mathbf{7}$ and $\mathbf{9}$ and both methyl and methoxyl substituents for case of $\mathbf{1 1}$.

\section{Single X-ray Crystal structure and conforma- tional search of 11}

The single-crystal structure of $\mathbf{1 1}$ was deduced by X-ray crystallography [32]. The space group of the molecular structure is $\mathrm{P} 2{ }_{1} / \mathrm{n}$, meaning the point group is $2 / \mathrm{m}$. An ORTEP drawing is shown in Figure 2 and the relevant crystallographic parameters are compiled in Table 1. The torsion angle $\mathrm{C} 18-\mathrm{C} 14-\mathrm{C} 15-\mathrm{C} 16$ and $\mathrm{C} 10-\mathrm{C} 11-\mathrm{C} 12-\mathrm{C} 13$ are $-174.40(13)^{\circ}$ and $-175.80(13)^{\circ}$ indicating that the benzene ring is slightly inwardly bend. The dihedral angles $\mathrm{C} 8-\mathrm{C} 6-\mathrm{C} 4-\mathrm{C} 5$ and $\mathrm{C} 5-\mathrm{C} 4-\mathrm{C} 2-\mathrm{C} 1$ are $-2.00(19)^{\circ}$ and $2.85(19)^{\circ}$, respectively; thereby implying that thienothiophene ring is also slightly inwardly bent. The thia bridges are anti oriented with respect to one another, and so are the two methoxyl groups. The angle of $104.13^{\circ}$ for $\mathrm{C} 10-\mathrm{S} 3-\mathrm{C} 9$ is slightly larger than $101.13^{\circ}$ for $\mathrm{C} 18-\mathrm{S} 4-\mathrm{C} 17$, presumably to minimized steric interaction between the methoxyl and methyl substituents on either sides of the bridges. The transannular distances between the bridgehead carbons $\mathrm{C} 11-\mathrm{C} 6$ and $\mathrm{C} 14-\mathrm{C} 2$ are $3.37 \AA$ and $3.32 \AA$, respectively and the phenyl and thieno- thiophene rings are stacked with the former slightly displaced from the center of the latter.

Table 1: Summary of crystallographic data and refinement details.

\begin{tabular}{|c|c|}
\hline Empirical formula & $\mathrm{C}_{20} \mathrm{H}_{22} \mathrm{O}_{2} \mathrm{~S}_{4}$ \\
\hline Formula mass & 422.66 \\
\hline Crystal color and habit & colorless, block \\
\hline Crystal size [nm] & $0.23 \times 0.21 \times 0.19$ \\
\hline Crystal system & monoclinic \\
\hline $\mathrm{a}[\AA]$ & $8.2943(5)$ \\
\hline$b[\AA]$ & $13.8204(9)$ \\
\hline$c[\AA]$ & $16.679(1)$ \\
\hline$\beta\left[^{\circ}\right]$ & $97.690(1)$ \\
\hline$V\left[\AA^{3}\right]$ & $1894.7(2)$ \\
\hline$\rho_{\text {calcd. }}\left[\mathrm{g} / \mathrm{cm}^{3}\right]$ & 1.482 \\
\hline$F(000)$ & 888 \\
\hline$\mu\left[\mathrm{cm}^{-1}\right]$ & $5.14(\mathrm{Mo}-\mathrm{K} \alpha)$ \\
\hline $2 \theta_{\max }\left[{ }^{\circ}\right]$ & $55.0(\mathrm{I}>3.0 \sigma)$ \\
\hline No. of reflections & 4039 \\
\hline
\end{tabular}

In order to evaluate the energy minimized conformations for $\mathbf{1 1}$, we performed the conformational analysis by random search Monte Carlo method [33] and optimized by PRCG Conjugated Gradient molecular mechanics minimization using the Macromodel version 5.5 program [34], MM2 force field [35] and GB/ SA chloroform solvation [36]. Two thousand conformations were generated from which we have selected three of the most

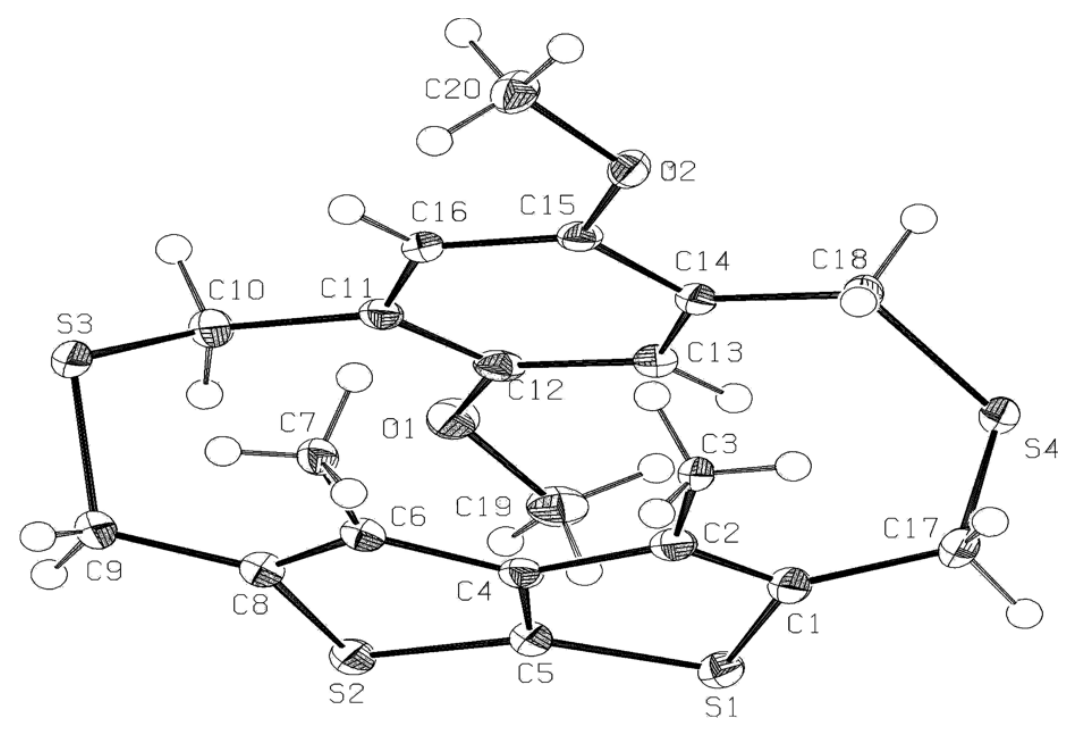

Figure 2: ORTEP plot of the crystal structure of 11. Important parameters: Bond length $(\AA)$ : C8-C9 = 1.492, C1-C7 = 1.497, C10-C11 = 1.517, C14-C18 = 1.522; Bond Angles (deg): C4, C6, C7 = 124.70, C1, C2, C3 = 125.03, C10, C11, C12 = 120.31, C13, C14, C18 = 123.14, C10, S3, C9 = 104.13; C18, S4, C17 = 101.14, C16, C11, C10 = 121.12 C15, C14, C18 = 118.43; Dihedral Angles (deg): C18, C14, C15, C16 = -174.40(13), C10, $\mathrm{C} 11, \mathrm{C} 12, \mathrm{C} 13=-175.43(14), \mathrm{C} 10, \mathrm{C} 11, \mathrm{C} 16, \mathrm{C} 15=178.80(13), \mathrm{C} 15, \mathrm{C} 16, \mathrm{C} 11, \mathrm{C} 12=-2.7(2), \mathrm{C} 12, \mathrm{C} 13, \mathrm{C} 14, \mathrm{C} 15=-3.1(2), \mathrm{C} 8, \mathrm{C} 6, \mathrm{C} 4, \mathrm{C} 6=$ $168.50(16), \mathrm{C} 1, \mathrm{C} 2, \mathrm{C} 4, \mathrm{C} 6=-167.65(16), \mathrm{C} 5, \mathrm{C} 4, \mathrm{C} 2, \mathrm{C} 1=5.29$. 
stable conformations within $12.55 \mathrm{~kJ} / \mathrm{mol}$ from the global minimum.

As depicted in Scheme 2, the notable difference between these conformations is the relative orientation of the bridging sulfur atoms with respect to the thienothiophene ring. The conformation designated as anti-11 is unsymmetrical with the bridging sulfur atoms being anti-oriented i.e. facing away from each other. The conformations syn-anti-11 and syn-syn-11 both have their bridge ' $S$ ' atoms symmetric about a plane bisecting the two rings, though they are not symmetric to the plane. Both conformations, syn-anti-11 and syn-syn-11 possess syn-oriented sulfur bridges, however: for the former the bridging sulfur atoms are pointing away from the sulfur atoms of the thienothiophene ring, while for the latter, the bridging sulfur atoms and the thienothiophene ring sulfur atoms are facing the same side. The key dihedral angles of these conformations together with those of $\mathbf{1 1}$ derived from the X-ray data are compiled in Table 2.
The conformation anti-11 is the lowest energy structure with ca. E of $-96.50 \mathrm{~kJ} / \mathrm{mol}$, while syn-anti-11 and syn-syn-11 are of relatively higher energy by ca. 2.98 and $12.55 \mathrm{~kJ} / \mathrm{mol}$, respectively. Inspection of Table 2 reveals that while some of the computed dihedral angles of the three most stable conformations are quite close to each other, the computed dihedral angles viz. S1-C1-C17-S4, C17-S4-C18-C14, C10-S3-C9-C8 and C8-S2-C5-S1 for the most stable anti-11 are broadly similar to those of the cyclophane $\mathbf{1 1}$ derived from the X-ray data. Consequently, there is good correspondence between the X-ray crystal structure and the most stable conformation anti-11 computed from the conformation energy minimization. Although, the $\Delta E$ between the most stable conformation anti-11 and the next higher energy conformation syn-anti-11 is only $2.98 \mathrm{~kJ} / \mathrm{mol}$, it is intriguing that $\mathbf{1 1}$ does not exhibit thia-bridge inversion even at elevated temperatures. The flipping of the thia-bridges in $\mathbf{1 1}$ as well as other cyclophanes described in the preceding section could be inhibited if the transition state structures have free energies of activation $>100 \mathrm{~kJ} / \mathrm{mol}$ [5]. This

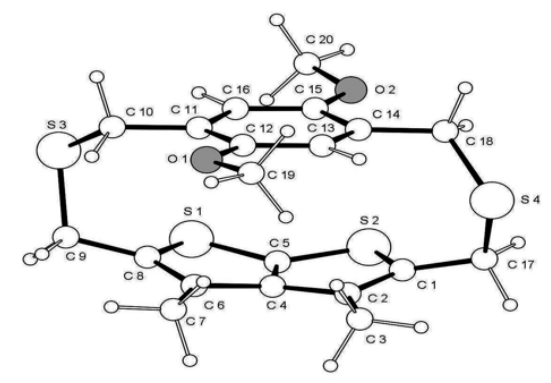

anti $11 ; E=-96.50 \mathrm{~kJ} / \mathrm{mol}$

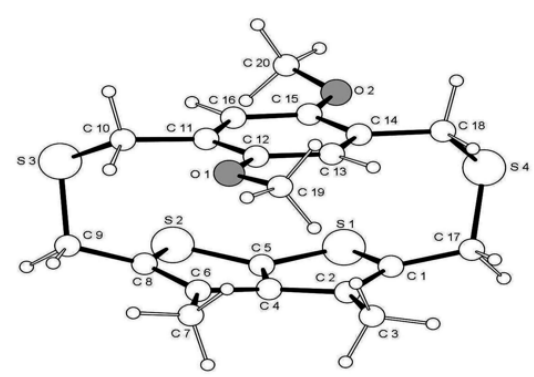

syn-anti $11 ; E=-93.52 \mathrm{~kJ} / \mathrm{mol}$

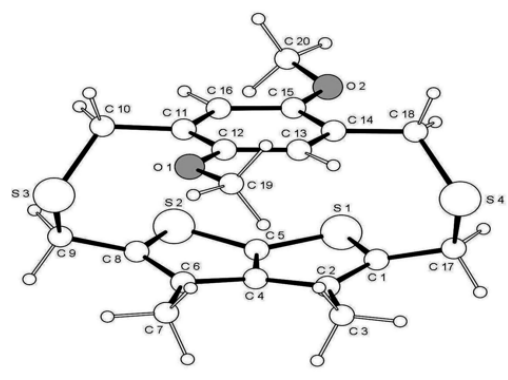

syn-syn 11; $E=-83.95 \mathrm{~kJ} / \mathrm{mol}$

Scheme 2: Computed three most stable conformations of 11 and their calculated energies.

Table 2: Selected computed dihedral angles (deg) of anti-11, syn-anti-11, and syn-syn-11 and those of 11 derived from the X-ray crystallography.

\begin{tabular}{|c|c|c|c|c|}
\hline & anti-11 & syn-anti-11 & syn-syn-11 & 11 \\
\hline$E$ in $\mathrm{kJ} / \mathrm{mol}$ & -96.50 & -93.52 & -83.95 & - \\
\hline$\Delta E$ in $\mathrm{kJ} / \mathrm{mol}$ & 0.00 & 2.98 & 12.55 & - \\
\hline S2-C5-S1-C1 & $-162.7^{\circ}$ & $+161.0^{\circ}$ & $-162.9^{\circ}$ & $168.61^{\circ}(13)$ \\
\hline C5-S1-C1-C17 & $+169.8^{\circ}$ & $-168.5^{\circ}$ & $+170.3^{\circ}$ & $-165.12^{\circ}(12)$ \\
\hline S1-C1-C17-S4 & $-61.3^{\circ}$ & $+51.8^{\circ}$ & $-120.4^{\circ}$ & $73.25^{\circ}(13)$ \\
\hline C1-C17-S4-C18 & $-67.0^{\circ}$ & $+71.9^{\circ}$ & $+63.0^{\circ}$ & $56.29^{\circ}(12)$ \\
\hline C17-S4-C18-C14 & $+78.9^{\circ}$ & $-69.8^{\circ}$ & $-74.9^{\circ}$ & $-85.25^{\circ}(12)$ \\
\hline C11-C10-S3-C9 & $+82.9^{\circ}$ & $+80.2^{\circ}$ & $+82.5^{\circ}$ & $-78.54^{\circ}(13)$ \\
\hline C10-S3-C9-C8 & $-58.2^{\circ}$ & $-68.3^{\circ}$ & $-60.3^{\circ}$ & $49.78^{\circ}(13)$ \\
\hline S3-C9-C8-S2 & $+113.3^{\circ}$ & $-61.8^{\circ}$ & $+112.5^{\circ}$ & $-106.16^{\circ}(12)$ \\
\hline C9-C8-S2-C5 & $-169.8^{\circ}$ & $+169.2^{\circ}$ & $-168.5^{\circ}$ & $169.94^{\circ}(13)$ \\
\hline C8-S2-C5-S1 & +163.6 & -161.7 & +162.4 & $-169.57(13)$ \\
\hline
\end{tabular}


aspect is currently being examined using molecular modeling approach.

\section{Conclusion}

In conclusion, we have reported the synthesis and structures of [3.3]dithia-bridged thienothiophenophanes 7, 9, and 11. Variable temperature ${ }^{1} \mathrm{H}$ NMR analysis revealed the absence of bridge flipping up to $130^{\circ} \mathrm{C}$ in these molecules. Phenyl ring rotation in cyclophanes $\mathbf{9}$ and $\mathbf{1 1}$ is also ruled out since separate singlets associated with phenyl protons (in case of $\mathbf{1 1}$, also the $-\mathrm{OCH}_{3}$ ) failed to coalesce up to $130{ }^{\circ} \mathrm{C}$. The structure of $\mathbf{1 1}$ was also deduced by a single crystal X-ray crystallography. The most stable conformation anti-11 derived from conformational minimization possessed broad structural similarity with that of the X-ray crystal structure.

\section{Experimental}

The chemicals and spectroscopic grade solvents were purchased from S.D.F. Chemicals (India) and Aldrich and used as received. IR spectra were recorded on a Shimadzu FTIR-420 spectrophotometer. ${ }^{1} \mathrm{H}$ NMR spectra were scanned in $\mathrm{CDCl}_{3}$ using a Bruker 300 or $700 \mathrm{MHz}$ spectrometer with TMS as an internal standard. Elemental analyses were done on a Carlo Erba instrument EA-1108 Elemental analyzer.

\section{Preparation of 3,4-dimethyl-2,5-bis(hydroxy- methyl)thieno[2,3-b]thiophene (4)}

A solution of diester thienothiophene 3 (1.56 g, $5 \mathrm{mmol})$ dissolved in dry THF $(20 \mathrm{ml})$ was added to a slurry of $\mathrm{LiAlH}_{4}$ $(950 \mathrm{mg}, 25 \mathrm{mmol})$ prepared in dry THF $(50 \mathrm{ml})$ at room temperature over a period of $1 \mathrm{~h}$. After stirring for $24 \mathrm{~h}$ at room temperature, the reaction mixture was cooled in an ice-salt bath and hydrolyzed by successive additions of water $(1 \mathrm{ml}), 15 \%$ sodium hydroxide $(1 \mathrm{ml})$ and water $(2.5 \mathrm{ml})$ with vigorous stirring. The reaction mixture was then filtered through celite and the filtered cake washed thoroughly with dry THF. The filtrate was concentrated to give diol $\mathbf{4}$ as a colorless solid (1.03 g, 91\% yield); mp: $156-158{ }^{\circ} \mathrm{C}$; IR (KBr) cm ${ }^{-1}: 3250,2921,2861$, 1525, 1443, 1418, 1399, 1353, 1234, 1191, 1125, 1113, 1003, 949, 700. ${ }^{1} \mathrm{H}$ NMR (DMSO, 300MHz) $\delta: 5.20(\mathrm{~s}, 2 \mathrm{H},-\mathrm{OH})$, $4.60\left(\mathrm{~s}, 4 \mathrm{H},-\mathrm{CH}_{2}-\right), 2.40\left(\mathrm{~s}, 6 \mathrm{H},-\mathrm{CH}_{3}\right)$. Anal. Calcd for $\mathrm{C}_{10} \mathrm{H}_{12} \mathrm{O}_{2} \mathrm{~S}_{2}$ : C, 52.63; H, 5.26; S, 28.07. Found $\mathrm{C}, 52.78 ; \mathrm{H}$, 5.49; S, 28.23.

\section{Preparation of 3,4-dimethyl-2,5-bis(chloro- methyl)thieno[2,3-b]thiophene (5)}

Diol 4 (1.14 g, $5 \mathrm{mmol}$ ) was stirred in dry dichloromethane and freshly distilled thionyl chloride $(1.0 \mathrm{ml}, 13.6 \mathrm{mmol})$ was added dropwise at $5-10{ }^{\circ} \mathrm{C}$. The reaction mixture was allowed to warm to room temperature over $5 \mathrm{~h}$. The reaction mixture was then concentrated and the obtained brown solid was boiled with light petroleum ether. The supernatant was transferred to a dry flask and the clear solution refrigerated overnight to furnish dichloride 5 as white-brownish solid (1.15 g, 88\% yield); mp $161-163{ }^{\circ} \mathrm{C}$; IR (KBr) cm ${ }^{-1}$ : 2923, 1520, 1436, 1422, 1395 , 1261, 1174, 1131, 1112, 862, 811, 673. ${ }^{1} \mathrm{H}$ NMR $\left(\mathrm{CDCl}_{3}, 300\right.$ $\mathrm{MHz}) \delta: 4.70\left(\mathrm{~s}, 4 \mathrm{H},-\mathrm{CH}_{2}\right), 2.50\left(\mathrm{~s}, 6 \mathrm{H},-\mathrm{CH}_{3}\right)$. Anal. Calcd for $\mathrm{C}_{10} \mathrm{H}_{10} \mathrm{Cl}_{2} \mathrm{~S}_{2}$ : C, 45.28; H, 37.74, S, 24.15, Cl, 26.42 Found C, 45.40; H, 37.57; S, 24.28, Cl, 26.35.

\section{Preparation of dithia[3]metacyclo[3] $(2,5)$ thienothiopheno- phane 7}

A solution of dichloride $5(265 \mathrm{mg}, 1 \mathrm{mmol})$ and 1,3bis(mercaptomethyl)benzene (6) (170 mg, $1 \mathrm{mmol})$ in dry DMF $(50 \mathrm{ml})$ was added dropwise to a stirred mixture of dry DMF $(100 \mathrm{ml})$ containing anhyd. $\mathrm{K}_{2} \mathrm{CO}_{3}(250 \mathrm{mg})$ at $60-70{ }^{\circ} \mathrm{C}$ over $8 \mathrm{~h}$ under $\mathrm{N}_{2}$ atmosphere. The reaction mixture was further stirred at this temperature for $16 \mathrm{~h}$. It was then allowed to cool and filtered through a pad of celite. The filtrate was concentrated in vacuum to give a dark-brown colored residue. The residual solid was extracted in chloroform, washed with water and dried over anhyd. $\mathrm{Na}_{2} \mathrm{SO}_{4}$. The crude product obtained on concentration was purified by column chromatography on $\mathrm{SiO}_{2}$ using petroleum ether-chloroform $(2: 1)$ as an eluant. The cyclophane 7 was obtained as a colorless solid, (207 mg, 57\%), m.p. 247-250 ${ }^{\circ} \mathrm{C}$; IR (KBr) cm ${ }^{-1}$ : 3008, 2947, 2907, 1583, 1482, 1428, 1396, 1228, 1215, 1082, 1009, 978, 780, 711. ${ }^{1} \mathrm{H}$ NMR $\left(\mathrm{CDCl}_{3}, 300 \mathrm{MHz}\right) \delta: 7.02(\mathrm{~s}, 3 \mathrm{H}, \mathrm{Ph}-\mathrm{H}), 6.03(\mathrm{~s}, 1 \mathrm{H}, \mathrm{Ph}-\mathrm{H})$, 4.30 (d, $2 \mathrm{H}, J=16 \mathrm{~Hz},-\mathrm{CH}_{2}$-thienothiophene), 3.82 (d, 2H, $J=$ $16 \mathrm{~Hz},-\mathrm{CH}_{2}$-thienothiophene), $3.56\left(\mathrm{~d}, 2 \mathrm{H}, J=16 \mathrm{~Hz},-\mathrm{CH}_{2}-\right.$ phenyl), 3.21 (d, $2 \mathrm{H}, J=16 \mathrm{~Hz},-\mathrm{CH}_{2}$-phenyl), 2.31(s, $6 \mathrm{H}$, $-\mathrm{CH}_{3}$ ). Mass : $\mathrm{m} / \mathrm{e} 362$. Anal. Calcd for $\mathrm{C}_{18} \mathrm{H}_{18} \mathrm{~S}_{4}$ : C, 59.67; H, 4.97; S, 35.36. Found C, 59.51; H, 4.93; S, 35.61.

\section{Preparation of}

\section{dithia[3]paracyclo[3] $(2,5)$ thienothiopheno- phane 9}

Dichloride 5 (265 $\mathrm{mg}, 1 \mathrm{mmol})$ and 1,4-bis(mercaptomethyl)benzene (8) (170 mg, $1 \mathrm{mmol}$ ) were coupled as described for 7 . The crude product was chromatographed on $\mathrm{SiO}_{2}$ column using petroleum ether-chloroform $(2: 1)$ as an eluant to afford cyclophane 9 as a colorless solid (180 mg, $50 \%$ ); mp 210-212 ${ }^{\circ} \mathrm{C}$; IR (KBr) cm ${ }^{-1}: 2922,1525,1504$, 1445, 1414, 1397, 1376, 1215, 1122, 1101, 1006, 892, 838, 791, 776, 722. ${ }^{1} \mathrm{H}$ NMR $\left(700 \mathrm{MHz}, \mathrm{CDCl}_{3}\right) \delta: 6.95(\mathrm{~s}, 2 \mathrm{H}, \mathrm{Ph}-\mathrm{H})$, $6.84(\mathrm{~s}, 2 \mathrm{H}, \mathrm{Ph}-\mathrm{H}), 4.08(2 \mathrm{H}, J=14 \mathrm{~Hz}), 3.73(2 \mathrm{H}, J=15 \mathrm{~Hz})$, $3.72(2 \mathrm{H}, J=14 \mathrm{~Hz}), 3.65(2 \mathrm{H}, J=15 \mathrm{~Hz}), 2.19\left(\mathrm{~s}, 6 \mathrm{H},-\mathrm{CH}_{3}\right)$. ${ }^{13} \mathrm{C} \mathrm{NMR}\left(300 \mathrm{MHz}, \mathrm{CDCl}_{3}\right) \delta: 147.37,136.20,135.11$, 133.80, 129.08, 126.07, 125.22, 36.07, 30.87, 13.72. Mass: m/e 362. Anal. Calcd for $\mathrm{C}_{18} \mathrm{H}_{18} \mathrm{~S}_{4}$ : C, 59.67; H, 4.97; S, 35.36 . Found C, 59.73; H, 4.81; S, 35.49. 


\section{Preparation of dimethoxydithia[3]paracyclo[3] $(2,5)$ thieno- thiophenophane 11}

Dichloride 5 (265 mg, $1 \mathrm{mmol}$ ) and 2,5-dimethoxy-1,4bis(mercaptomethyl)benzene (10) $(156 \mathrm{mg}, 1 \mathrm{mmol})$ were coupled as described for 7 . The crude product was chromatographed on $\mathrm{SiO}_{2}$ using petroleum ether-chloroform (2:1) as an eluant to afford cyclophane $\mathbf{1 1}$ as a colorless solid (23 mg, 10\% yield); $\mathrm{mp} 252-253{ }^{\circ} \mathrm{C}$. IR (KBr) cm $\mathrm{cm}^{-1}: 2988,2950,2836$, 1606, 1576, 1492, 1459, 1446, 1409, 1308, 1231, 1196, 1042, 1007, 890, 864, 769, 749. ${ }^{1} \mathrm{H}$ NMR $\left(300 \mathrm{MHz}, \mathrm{CDCl}_{3}\right) \delta: 6.80$ (s, 2H, Ph-H), $4.30\left(\mathrm{~d}, 1 \mathrm{H}, J=14 \mathrm{~Hz},-\mathrm{CH}_{2}\right), 4.14(\mathrm{~d}, 1 \mathrm{H}, J=$ $\left.17 \mathrm{~Hz},-\mathrm{CH}_{2}\right), 4.02\left(\mathrm{~d}, 1 \mathrm{H}, J=18 \mathrm{~Hz},-\mathrm{CH}_{2}\right), 3.9$ (d, $1 \mathrm{H}, J=17$ $\left.\mathrm{Hz},-\mathrm{CH}_{2}\right), 3.81\left(\mathrm{~d}, 1 \mathrm{H}, J=14 \mathrm{~Hz},-\mathrm{CH}_{2}\right), 3.58(\mathrm{~d}, 1 \mathrm{H}, J=15$ $\left.\mathrm{Hz},-\mathrm{CH}_{2}\right), 3.44\left(\mathrm{~d}, 1 \mathrm{H}, J=18 \mathrm{~Hz},-\mathrm{CH}_{2}\right), 3.36(\mathrm{~d}, 1 \mathrm{H}, J=14$ $\left.\mathrm{Hz},-\mathrm{CH}_{2}\right), 3.75\left(\mathrm{~s}, 3 \mathrm{H},-\mathrm{OCH}_{3}\right), 3.80\left(\mathrm{~s}, 3 \mathrm{H},-\mathrm{OCH}_{3}\right), 2.22$ (s, $\left.3 \mathrm{H},-\mathrm{CH}_{3}\right), 2.29$ (s, $\left.3 \mathrm{H},-\mathrm{CH}_{3}\right)$. Mass: $\mathrm{m} / \mathrm{e} 422$. Anal. Calcd for $\mathrm{C}_{20} \mathrm{H}_{22} \mathrm{O}_{2} \mathrm{~S}_{4}$ : C, 56.87; H, 5.21; S, 30.33. Found C, 56.94; H, $5.45 ; \mathrm{S}, 30.19$.

\section{Acknowledgments}

We thank the NMR facility at IISc., Bangalore for providing $700 \mathrm{MHz}$ NMR spectra and University of Mumbai for research fellowship to S. G.

\section{References}

1. Keehn, P. M.; Rosenfeld, S. M., Eds. Cyclophanes; Academic Press: New York, 1983; Vol. I and II.

2. Vogtle, F. Cyclophane Chemistry; Wiley-VCH: Chichester, 1993.

3. Gleiter, R.; Hopf, H., Eds. Modern Cyclophane Chemistry; Wiley-VCH: Weinheim, 2004.

4. Lehn, J.-M. Supramolecular Chemistry. Concepts and Perspectives; Wiley-VCH: Weinheim, 1995.

5. Mitchell, R. H. In Cyclophanes; Keehn, P.; M and Rosenfeld, S. M., Eds.; Academic Press: New York, 1983; Vol. 1, pp 239-310.

6. Ernst, L. Prog. Nucl. Magn. Reson. Spectrosc. 2000, 37, 47-190. doi:10.1016/S0079-6565(00)00022-4

7. Mitchell, R. H.; Weerawarna, K. S.; Bushnell, G. W. Tetrahedron Lett. 1984, 25, 907-910. doi:10.1016/S0040-4039(01)80059-9

8. Xu, J.-W.; Lin, T.-T.; Lai, Y.-H. Tetrahedron 2005, 61, 2431-2440. doi:10.1016/j.tet.2005.01.027

9. Bodwell, G. J.; Ernst, L.; Hopf, H.; Jones, P. G.; McNally, J. P.; Schomburg, D. Chem. Ber. 1990, 123, 2381-2386. doi:10.1002/cber.19901231221

10. Haenel, M. W. Chem. Ber. 1982, 115, 1425-1436. doi:10.1002/cber.19821150421

11. Yamato, T.; Miyazawa, A.; Tashiro, M. J. Chem. Soc., Perkin Trans. 1 1993, 3127-3137. doi:10.1039/P19930003127

12. Ernst, L.; Ibrom, K. Angew. Chem. 1995, 34, 1881-1882. doi:10.1002/anie.199518811

13. Fukazawa, Y.; Ohta, E.; Nakabai, T.; Usui, S. Chem. Lett. 1987, 12, 2345-2346.

14. Lai, Y.-H.; Ang, S.-G.; Wong, S.-Y. Tetrahedron Lett. 1997, 38 , 2553-2556. doi:10.1016/S0040-4039(97)00399-7
15. Mashraqui, S. H.; Keehn, P. M. J. Org. Chem. 1983, 48, 1341-1344. doi:10.1021/jo00156a037

16. Mashraqui, S. H.; Sanghvikar, Y. S.; Meetsma, A. Tetrahedron Lett. 2006, 47, 5599-5602. doi:10.1016/j.tetlet.2006.05.098

17. Mashraqui, S. H.; Kumar, S.; Dau, E. T. H. J. Mol. Struct. 2004, 697, 221-230. doi:10.1016/j.molstruc.2004.04.014

18. Ueda, T.; Kanomata, N.; Machida, H. Org. Lett. 2005, 7, 2365-2368. doi:10.1021/ol0506258

19. Butler, D. N.; Shang, M.; Warrener, R. N. Tetrahedron Lett. 2000, 41, 5985-5989. doi:10.1016/S0040-4039(00)00956-4

20. Grimme, S. Chem.-Eur. J. 2004, 10, 3423-3429. doi:10.1002/chem.200400091

21. Mashraqui, S. H.; Ashraf, M.; Hariharasubrahmanian, H.; Kellogg, R. M.; Meetsma, A. J. Mol. Struct. 2004, 689, 107-113. doi:10.1016/j.molstruc.2003.10.026

22. Mashraqui, S. H.; Ghadigaonkar, S.; Ashraf, M.; SriRanjini, A.; Ghosh, S.; Das, P. K. Tetrahedron 2007, 63, 10011-10017. doi:10.1016/j.tet.2007.07.059

23. Mashraqui, S. H.; Sanghvikar, Y.; Ashraf, M.; Kumar, S.; Trân Huu Dâub, E. Tetrahedron 2005, 61, 3507-3513. doi:10.1016/j.tet.2005.01.123

24. Mashraqui, S. H.; Sanghvikar, Y. S.; Meetsma, A. Tetrahedron Lett. 2006, 47, 5599-5602. doi:10.1016/j.tetlet.2006.05.098

25. Mashraqui, S. H.; Hariharasubramanian, H.; Kumar, S. Synthesis 1999, 12, 2030-2032. doi:10.1055/s-1999-3631

26. Oki, M. Applications of Dynamic NMR Spectroscopy to Organic Chemistry. In Methods in Stereochemical Analysis; Marchand, A. P., Ed.; VCH Publishers: Deerfield Beach, Florida, 1985; Vol. 4, pp 234 ff.

27. Sato, T.; Wakabayashi, H. M.; Kainosho, K. M. Tetrahedron 1971, 27, 2737-2755. doi:10.1016/S0040-4020(01)98064-0

28. Lai, Y.-H.; Yap, A. H.-T. J. Chem. Soc., Perkin Trans. 2 1993, 7, 1373-1377. doi:10.1039/p29930001373

29. Lai, Y.-H.; Yap, A. H.-T.; Novak, I. J. Org. Chem. 1994, 59, 3381-3385. doi:10.1021/jo00091a027

30. Sherrod, S. A.; Boekelheide, V. J. Am. Chem. Soc. 1972, 94, 5513-5515. doi:10.1021/ja00770a066

31. Staab, H. A.; Herz, C. P. Angew. Chem., Int. Ed. Engl. 1977, 16, 799-801. doi:10.1002/anie.197707991

32. The X-ray crystal structure data have been submitted to the Cambridge Database as a file CCDC-297142.

33. Chang, G.; Guida, W. C.; Still, W. C. J. Am. Chem. Soc. 1989, 111, 4379-4386. doi:10.1021/ja00194a035

34. Mohamadi, F.; Richards, N. J. G.; Guida, W. C.; Liskamp, R.; Lipton, M. C.; Caufield, M.; Chang, G.; Hendrickson, T.; Still, W. C. J. Comput. Chem. 1990, 11, 440-467. doi:10.1002/jcc.540110405

35. Allinger, N. L. J. Am. Chem. Soc. 1977, 99, 8127-8134. doi:10.1021/ja00467a001

36. Still, W. C.; Tempczyk, A.; Hawley, R. C.; Hendrickson, T. J. Am. Chem. Soc. 1990, 112, 6127-6129. doi:10.1021/ja00172a038 


\section{License and Terms}

This is an Open Access article under the terms of the Creative Commons Attribution License

(http://creativecommons.org/licenses/by/2.0), which permits unrestricted use, distribution, and reproduction in any medium, provided the original work is properly cited.

The license is subject to the Beilstein Journal of Organic Chemistry terms and conditions:

(http://www.beilstein-journals.org/bjoc)

The definitive version of this article is the electronic one which can be found at:

doi:10.3762/bjoc.5.74 